\title{
DO ALTAR ÀS RUAS: UMA ANÁLISE DO FUNDAMENTALISMO RELIGIOSO NO BRASIL.
}

\author{
Kaliane Santos Oliveira \\ Email :Kali.oliveira41@gmail.com \\ Universidade Estadual Paulista “ Júlio de Mesquita Filho”-FFC Marília
}

\section{RESUMO}

Este trabalho possui como objetivo apresentar a relação política e religião no Brasil contemporâneo. Nosso enfoque reside no líder religioso Silas Malafaia e sua empresa da fé Associação Vitória em Cristo (AVEC) e sua igreja Assembleia de Deus Vitória em Cristo. Sustenta-se a hipótese que mediante a recursos midiáticos como televisão e redes sociais o líder religioso consegue construir uma série de seguidores que fortalece suas ideologias ligadas a defesa da família tradicional. As utilizações dos discursos proferidos pelo pastor são capazes de modificar e moldar a identidade de seus féis que enxergam na figura do Silas Malafaia o exemplo do cidadão guiado pelos ensinamentos de Deus. Os impactos dessa prática na vida pública podem resultar em cidadãos intolerantes que centralizam a fé e a figura divina como explicação e resolução para os problemas públicos e pessoais. A análise desses efeitos se realiza mediante ao exame de recursos primários e secundários e materiais de jornais e vídeos publicados pelo líder religioso. Busca-se confirmar a relação entre religião e a construção da identidade do homem político no cenário do Brasil contemporâneo.

Palavras Chaves: Silas Malafaia; Identidade; Religião; Neopentecostalismo.

\begin{abstract}
This work aims to present the political relationship and religion in contemporary Brazil. Our focus is on the religious leader Silas Malafaia and your company's faith in Christ Victory Association (AVEC) and his God Victory Assembly Church in Christ. It is argued that the assumption by the media resources such as television and social networks religious leader can build a number of followers that strengthens their ideologies linked to defense of the traditional family. The use of speeches delivered by the pastor are able to modify and shape the identity of their faithful who see in the figure of Silas Malafaia the example of citizens guided by the teachings of God. The impacts of this practice in public life can result in intolerant citizens which centralize faith and divine figure as an explanation and resolution for public and personal problems. The analysis of these effects is achieved through the examination of primary and secondary resources and materials from newspapers and videos published by the religious leader. The aim is to confirm the relationship between religion and the construction of the identity of the politician on the scene of contemporary Brazil.
\end{abstract}

Key words: Silas Malafaia; Identity, Religion, Neo-Pentecostalism 


\section{SEMINÁRIO DE PESQUISA EM CIÊNCIAS HUMANAS - SEPECH \\ Humanidades, Estado e desafios didático-científicos \\ Londrina, 27 a 29 de julho de 2016}

\section{INTRODUÇÃO}

As primeiras igrejas pentecostais estabelecidas no Brasil foram a Congregação Cristã do Brasil (1910) e Assembleia de Deus (1911), com algumas características similares obtiveram grande sucesso em sua instalação, estando presente até dos dias atuais com um crescente avanço Com características clássicas, estas igrejas são referências quando se trata de dons da cura e glossolalia com a imensa preocupação com a vida nos céus, durante sua trajetória não privilegiou aspectos da vida "mundana" como a política, economia e assuntos ligados a governabilidade do Estado, deixando o crente limitado a assuntos da igreja e sua salvação.

Ao longo dos anos foram instaladas diversas outras vertentes do pentecostalismo no Brasil, a partir da década de 1950 com a chegada do Evangelho Quadrangular ocorre a fragmentação do pentecostalismo não só carregadas de nomenclaturas diferentes, mas com pregações que não se interligam. A Igreja Brasil para Cristo (1956), Igreja Pentecostal Deus é Amor (1962), Igreja Nova Vida (1960),são oriundas dessa fragmentação, mas possuem características clássicas do pentecostalismo. Todas essas igrejas surgiram com a ajuda das rádios, com pregações diárias que estimulavam o fiel a contribuir para a construção dos templos de oração.

Uma característica do Neopentecostalismo que surge na década de 1970, já estava presente no pentecostalismo clássico, o uso de mídias para propagação de pregações. Esse recurso será empregado massivamente pelas novas igrejas, sendo uma de suas ferramentas principais para captação de novos fiéis.

A Igreja Universal do Reino de Deus (1977) nasceu com grande influência da Igreja Nova Vida, se tornando a pioneira do uso de recursos midiáticos. Devido ao seu grande crescimento a ampliação do uso de rádio e posteriormente o de canais de TV com a abrangência nacional, possibilitou a integração do fiel que não podia estar de corpo presente nos templos de oração. Os impactos do uso desses instrumentos colaborou para o aumento de números de crentes da Igreja Universal, possibilitando a expansão da construção de templos e ampliação dos meios de comunicação. As outras igrejas, frente ao crescimento exponencial da IURD, seguiram o mesmo protocolo, passando assim, a comprar espaços nos canais de televisão, rádios e propagandas enaltecendo Deus como a chave do sucesso.

A igreja Assembleia, oriunda do pentecostalismo clássico, aos poucos começa a adotar as características das igrejas neopentecostais como: Sara Nossa Terra (1980), Renascer em Cristo (1986) e Igreja Universal do Reino de Deus. Gradativamente a Assembleia de Deus vai introduzindo aspectos midiáticos em sua abordagem com seus fiéis, a fim de alcançar o sucesso que a Igreja Universal do Reino de Deus conquistou. A escolha de adotar novos meios para obter o aumento do número de fiéis obteve sucesso, a construção de novos templos e a ampliação de recursos de acessos para atingir novos fiéis possibilitaram um maior reconhecimento por parte da comunidade evangélica.

A igreja Assembleia de Deus é a maior igreja pentecostal do Brasil,segundo o censo realizado pelo Instituto Brasileiro de Geografia e Estática (IBGE) no ano de 2010 


\title{
XI SEMINÁRIO DE PESQUISA EM CIÊNCIAS HUMANAS - SEPECH \\ Humanidades, Estado e desafios didático-científicos \\ Londrina, 27 a 29 de julho de 2016
}

com um número de 12.314.410 fiéis espalhados pelo Brasil. Esse número é capaz de nos mostrar a grande influência que a igreja possui frente ao exponencial número de fiéis ao longo dos anos.

Neste artigo vamos nos atentar especificamente a igreja Assembleia de Deus Vitória em Cristo, que é um dos objetos principais de análise da pesquisa. Com o surgimento datado no ano de 1959, a Assembleia de Deus Vitória em Cristo, era anteriormente intitulada de Assembleia de Deus da Penha e seguia preceitos característicos do pentecostalismo clássico, contudo no ano de 2010 o pastor e atual líder Silas Malafaia assume a direção da igreja, o que posteriormente acarretou na mudança de nome da instituição e algumas mudanças estruturais no funcionamento.

A partir da entrada do líder Silas Malafaia, a igreja passa a aderir aspectos ainda mais expansionistas, transformando a mesma em moldes análoga a uma empresa, com investimento em infraestrutura, mídias, capacitação de líderes e inserção da igreja nas redes sociais com publicação de mensagens diárias e vídeos com opiniões de comportamento e política, agindo com grande influência na construção de opinião de seus expectadores. Ao publicar mensagens e pedidos de

inserção de seus fiéis no meio político e social, a igreja Assembleia de Deus quebra com uma das características fundamentais do pentecostalismo clássico, o crente a partir de então deve emitir opinião no meio político e se envolver com assuntos ligados ao meio social. Ricardo Mariano (1999) em seu livro "Neopentecostais: Sociologia do Novo Pentecostalismo no Brasil" explica este rompimento com o pentecostalismo tradicional.

\begin{abstract}
"Outra característica dos neopentecostais reside no rompimento com a ideia da busca da salvação pelo ascetismo de rejeição do mundo. Com isso, contrariam frontalmente a velha proposição pentecostal (forjada quando os crentes não contavam em seu meio com segmentos de classe média e muito menos com empresários, políticos, artistas e atletas de renome) de que a existência terrena do verdadeiro cristão seria dominada pela pobreza material e pelo sofrimento da carne." (Mariano. 1999, pag. 44)
\end{abstract}

Essa quebra com o pentecostalismo clássico molda uma nova identidade para o fiel da Assembleia de Deus, inovando questões doutrinarias relacionadas a vestimentas, vaidade e até mesmo acesso a meios de comunicação que anteriormente eram restritas. O mundanismo faz parte da vida do crente e o mesmo possui como missão propagar os ensinamentos cristãos em todas as esferas da sociedade, em todos lugares, esse argumento é muito eficaz no sentindo de justificar a adesão da igreja Assembleia de Deus ao Neopentecostalismo.

A aderência deste novo modo de pensar da igreja, gerou consequências muitas vezes, inesperadas para a sociedade. A igreja passou a cobrar posicionamentos cristão na sociedade, que é laica, se interferindo em assuntos que antes não estavam presentes no âmbito cristão como a questão do aborto, legalização de drogas, homo afetividade e no cenário político. Estes novos posicionamentos foram formados ao longo do tempo pela grande influência da igreja que em cultos e por meio das mídias tratavam 


\section{SEMINÁRIO DE PESQUISA EM CIÊNCIAS HUMANAS - SEPECH \\ Humanidades, Estado e desafios didático-científicos \\ Londrina, 27 a 29 de julho de 2016}

determinados assuntos cobrando participação ativa do cristão. $\mathrm{O}$ arcabouço ideológico do Neopentecostalismo foi capaz de mudar a identidade do homem cristão, transformando-o em intolerante, autoritário e fundamentalista, se utilizando da fé para propagar preconceitos.

Uma pequena busca na internet por vídeos do pastor Silas Malafaia, encontramos facilmente vídeos com diversos títulos que incentivam a cultura do ódio e o preconceito político. Peguemos como análise o vídeo intitulado" O Boticário, Parada Gay e PT" (8/06/2015) o pastor comenta o comercial da marca de cosméticos concomitante com a crítica a parada gay e a gestão do governo PT, que para o pastor poderia ser um possível culpado.

Algumas de suas falas em seus vídeos deixa explícito o incentivo ao ódio como: " Liberdade de expressão e de imprensa é para ativismo gay, pois quando os outros querem falar de comportamento é homofobia. Opinião não é homofobia, opinião não é crime. Eu sou livre! ". "Quem usar a grande mídia para fazer ativismo gay eu vou me posicionar"; "O governo do PT deram mais de milhões para promover a causa gay”.

Estas falas do líder religioso são acompanhadas de um tom agressivo e a ideia de permissividade do crente em opinar nessas questões. Os vídeos publicados por Silas Malafaia diariamente possuem conteúdo analítico e educativo para seus fiéis, moldando sua opinião frente a essas questões que anteriormente não faziam parte da vida do cristão da Assembleia de Deus.

\section{ANTIGO CRISTÃO, NOVO CIDADÃO}

Com as mudanças estruturais acarretadas pelo Neopentecostalismo o crente já não é mais visto apenas como um simples evangélico, mas sim como um cidadão a serviço da palavra de Deus. Com a missão de estar presente em todos âmbitos da sociedade levando os verdadeiros ensinamentos de cristo, agora o evangélico se coloca na obrigação de estar presente em esferas em que anteriormente não tinha nem conhecimento de como funciona.

Silas Malafaia trabalha constantemente para que alguns de seus fiéis e aliados consigam adentrar em espaços que não fazia parte do crente. A Escola de Líderes Vitória em Cristo (ELASVEC) e o investimento na formação não é vão. Com sua influência na formação de opinião de seus fiéis, conseguiu grande influência na bancada evangélica na câmara que conta com 196 deputados evangélicos, sendo os partidos com o maior número de deputados evangélicos o PMDB e PSD. Os números explicam a intensa guerra que Silas Malafaia faz a alguns partidos que o mesmo acredita serem de esquerda como PT e PSOL incentivando o ódio a estes partidos na política um bom exemplo é o vídeo do pastor intitulado "Governo Dilma Burla Lei para destruir Família", mostrando para o crente que o governo se coloca claramente contra um bem precioso para os cristãos que é a família tradicional. 


\section{SEMINÁRIO DE PESQUISA EM CIÊNCIAS HUMANAS - SEPECH \\ Humanidades, Estado e desafios didático-científicos \\ Londrina, 27 a 29 de julho de 2016}

Sua influência no meio político é de extrema importância, tanto que Silas Malafaia, nas últimas eleições presidências no ano de dois mil e quatorze concedeu total apoio ao candidato a presidência da república Pr.Everaldo Dias Pereira- PSC ( Partido Social Cristão) incentivando seus fiéis por meio do voto e da fé eleger o único líder capaz de atender aos interesses de uma multidão de fiéis com o grande anseio de prosperar. Com plano político apresentado para concorrer às eleições, Pr. Everaldo defendia questões como: a vida humana já entendida no momento da sua concepção, economia livre a partir do empreendedorismo individual, proteção da vida e da família e parcerias entre público e privado a fim de favorecer a concorrência. Tais políticas atenderiam aos interesses de grandes empresas e não de seus fiéis que majoritariamente fazem parte da classe trabalhadora, elucidando cada vez mais que seu império da fé nada mais é que o instrumento para enriquecimento pessoal e assistência para a política de direita no Brasil.

O candidato apoiado por Silas Malafaia, obteve aproximadamente $0,75 \%$ dos votos o que corresponde a 780.513 de eleitores, número bastante significativo para um candidato com propostas demasiadamente conservadoras.

O crente neopentecostal não possui somente os anseios de ir viver no céu com Deus, mas busca riquezas na terra. Todo esse desejo é potencializado pelas pregações feitas nos templos de oração, que glorificam o crente que é próspero em detrimento do crente não próspero. Toda a prosperidade só é garantida por meio da fé, sendo o fiel o único responsável pelo seu enriquecimento. Para que a prosperidade seja plenamente atingida o crente deve orar, jejuar, dar dízimos, comprar livros e até mesmo votar em candidatos que representam os homens de Deus na política.

\footnotetext{
"O apego dos neopentecostais ao mundo é indisfarçável. Em contraste, sobretudo, com o pentecostalismo clássico que enfatiza a salvação celestial e exorta constantemente o fiel a permanecer firme na fé diante da proximidade do juízo final, a preocupação primordial que transparece na mensagem neopentecostal é com esta vida e com este mundo. O que interessa é o aqui e agora. E, para isso, nada melhor do que ter Cristo no coração o meio infalível de alcançar a vitória sobre o Diabo e obter a retribuição divina agora e sempre. A teologia do domínio e a teologia da prosperidade, ao dedicarem-se exclusivamente a este mundo e a esta vida, para resolver magicamente os problemas cotidianos dos fiéis, distanciam o Neopentecostalismo da escatologia pentecostal clássica, pré milenarista, baseada na eterna e resignada espera do retorno de cristo. Escatologia, frisa-se, que tendia a levar ao apoliticismo, a auto exclusão da vida social e ao ascetismo intramundano" (Mariano. 1999, pag. 44)
}

O crente já não é mais o mesmo que entrou. Esta frase é enfatizada constantemente pela igreja, elucidando a mudança de parâmetros do pentecostalismo clássico como algo bom. A mulher que somente usava saias longas agora pode usar calças jeans, a vaidade com maquiagens e joias podem ser utilizadas, os carros, investimentos e a valorização do empreendedorismo possuem até mesmo cultos específicos ,com ofertas especificas para incentivar o crente ao um novo estilo de vida. 


\section{SEMINÁRIO DE PESQUISA EM CIÊNCIAS HUMANAS - SEPECH \\ Humanidades, Estado e desafios didático-científicos \\ Londrina, 27 a 29 de julho de 2016}

“ O pentecostalismo herda a postura de rejeição e afastamento do mundo diretamente do metodismo e do movimento Holiness, dos quais se originou. Provém daí as raízes puritana e pietista do movimento pentecostal, mostra-se santificado, e ele precisa exteriorizar sinais, por meio de comportamentos ensinados e exigidos pela comunidade religiosa, que os diferenciem da sociedade inclusiva. Assim procedendo, ele denota sua condição de salvo em Cristo. A fim de atingir a perfeição cristã, para onde caminha espiritualmente aquele que renasce em Cristo, é fundamental que o crente, como vaso e templo do Espírito Santo, afasta-se dos prazeres interesses e paixões do mundo. Para não serem contaminados e corrompidos pelas coisas, paixões e interesses do mundo, os líderes pentecostais procuram imprimir na conduta dos fiéis, desde a conversão, normas e tabus comportamentais, valores morais, usos costumes de santificação. Infundem neles o desejo de viver o evangelho de acordo com o mais puro ascetismo de rejeição do mundo, segundo a definição weberiana, de modo a distanciá-los de coisas, atitudes, valores e instituições do incrédulo porém, tentador mundo circundante. "( Mariano,1999,pag190)

Baseado na teologia da prosperidade as igrejas neopentecostais brasileiras se utilizam desta teoria para pregar a prosperidade por meio da fé, sendo o sucesso produzido único e exclusivamente pelo fiel. O discurso utilizado pelos pastores que aderem a esta teoria é que Deus tem um plano para vida de cada um de nós e a prosperidade é uma delas. Diferente do pentecostalismo tradicional, a coisa terrena agora tem importância. O crente deve andar bem-vestido com roupas de marcas, relógios caros, carros de luxo e ter um bom imóvel. A explicação surge do fato de que Deus, quer o melhor para nós, sendo assim, cabe ao crente desfrutar dos bens materiais do mundo que Deus proporciona.

As opiniões no âmbito social e político seguem uma linha conservadora com um maior caráter fundamentalista, sendo cada vez mais intolerantes com homossexuais, religiões afros e comunistas sempre se utilizando da bíblia para pautar os preconceitos. A igreja não só cria pessoas intolerantes mas potencializa a intolerância de seus fiéis se pautando em uma verdade universal inexistente

\section{CONCLUSÃO}

Ao decorrer dos anos o pentecostalismo foi tomando várias formas, desde omissa a assuntos sociopolíticos até a participação ostensiva. Contudo, o problema não está em sua participação em si, mas no que a mesma acarreta. O papel da igreja na vida do fiel é análogo a educação escolar, no qual o indivíduo forma bases para o convívio social, mas quando as bases modificam ou potencializa preconceitos e intolerâncias a religião acaba por ser tonar nociva para a sociedade. Em uma religião no qual, a comunhão e o amor são bases para a vida do indivíduo incitações de ódio a determinados grupos e pensamentos diversos, se mostra de uma forma inconsistente em relação ao mote cristão de amar ao próximo. A sociedade não precisa de indivíduos 


\section{SEMINÁRIO DE PESQUISA EM CIÊNCIAS HUMANAS - SEPECH \\ Humanidades, Estado e desafios didático-científicos \\ Londrina, 27 a 29 de julho de 2016}

agressivo, fundamentalistas que interpretam a bíblia a seu modo. Toda e qualquer representação de fé é permitido, o que não podemos aceitar é a ampliação de preconceitos e ódio ao diferente. O papel destas igrejas deve ser constantemente analisado, precisamos estar atentos as reais consequências concretas que elas acarretam para sociedade nos espaços políticos e sociais.

\section{BIBLIOGRAFIA}

MARIANO, Ricardo. Neopentecostais: Sociologia do Novo Pentecostalismo No Brasil. São Paulo: Editora Loyola, 1999.

http://www.ibge.gov.br/estadosat/temas.php?tema $=$ censodemog2010 relig\# ( acesso $15 / 05 / 2016)$

http://top10mais.org/top-10-maiores-denominacoes-evangelicas-do-brasil-censo-2010/ ( acesso 15/05/2016)

https://www.youtube.com/watch?v=3NM1ihmbmK0 (acesso 8/06/2015)

https://www.youtube.com/watch?v=NH-DmidYJv8 (acesso 24/06/2015)

https://www.youtube.com/watch?v=LIUf43ugT9s （acesso 24/06/2015)

http://www.valor.com.br/eleicoes-2014/apuracao (acesso 15/05/2016) 